\title{
Perancangan Regulasi Tegangan AC - DC Menggunakan Filter Pasif
}

\author{
Agus Prasetyo, Fajar Bima D.R, Hendi Matalata* \\ Jurusan Teknik Listrik, Fakultas Teknik, Universitas Batanghari \\ "Corresponding e-mail: hendi.matalata@unbari.ac.id
}

\begin{abstract}
Abstrak_ Adaptor/catu daya adalah sumber tegangan DC yang digunakan untuk memberikan tegangan atau daya kepada berbagai rangkaian elektronika yang membutuhkan tegangan DC agar dapat beroperasi. Rangkaian pokok dari catu daya tidak lain adalah suatu penyearah yakni suatu rangkaian yang mengubah sinyal bolak-balik (AC) menjadi sinyal searah (DC. Proses pengubahan dimulai dari penyearahan oleh diode. Pada paper ini penghalusan tegangan kerut (Ripple Voltage Filter) dilakukan dengan menggunakan filter pasif dan didapat drop tegangan dari filter rata-rata sebesar $64 \%$, pengaturan (regulasi) oleh rangkaian regulator, penyediaan sumber energi listrik DC ini adalah untuk penyediaan tegangan variabel searah (DC) yang bertujuan untuk Penyediaan alat praktek pada labor listrik universitas batanghari adapun manfaat yang didapat dari hasil penelitian adalah sebagai alat untuk keperluan kegiatan praktek di labor teknik listrik Universitas Batanghari Jambi
\end{abstract}

Kata Kunci : Adaptor,Filteri,Regulator

Abstract_ The adapter / power supply is a DC voltage source that is used to provide voltage or power to various electronic circuits that require DC voltage to operate. The main circuit of the power supply is a rectifier, which is a circuit that converts an alternating signal $(A C)$ into a direct signal $(D C)$. The conversion process starts from rectification by the diode. In this paper, the Ripple Voltage Filter is carried out using a passive filter and the average voltage drop of the filter is $64 \%$, the regulation (regulation) by the regulator circuit, the provision of this DC electrical energy source is to provide a unidirectional variable voltage (DC) which aims to provide practical tools in Batanghari University electric laboratories while the benefits obtained from the research results are as a tool for practical activities in the electrical engineering laboratory of Batanghari University, Jambi.

Keywords : Rectifier, Filter, Regulator

\section{PENDAHULUAN}

Saat ini energi listrik menjadi suatu kebutuhan pokok yang sangat penting bagi kehidupan manusia. Bukan hanya untuk industri besar, bagi golongan masyarakat kecilpun listrik juga mejadi sangat esensial untuk kehidupan sehari-hari. Dengan adanya energi ini listrik, manusia dapat melakukan aktivitasnya dengan efektif dan efesien sehingga dapat meningkatkan kesejahteraan hidup manusia. Kebutuhan sumber daya listrik dapat diperoleh dari baterai, solar sel, generator AC/DC, dan jala-jala listrik PLN. Berbagai sumber daya tersebut akan kita bahas salah satunya type catu daya yang terjadi melalui suatu proses pengubahan dari tegangan AC (bolak-balik) ke DC (searah)[1].

Adaptor/catu daya adalah sumber tegangan DC yang digunakan untuk memberikan tegangan atau daya kepada berbagai rangkaian elektronika yang membutuhkan tegangan DC agar dapat beroperasi. Rangkaian pokok dari catu daya tidak lain adalah suatu penyearah yakni suatu rangkaian yang mengubah sinyal bolak-balik (AC) menjadi sinyal searah (DC). Proses pengubahan dimulai dari penyearahan oleh diode, penghalusan tegangan kerut (Ripple Voltage Filter) dengan menggunakan condensator dan pengaturan (regulasi) oleh rangkaian regulator. Pengaturan meliputi pengubahan tingkat tegangan atau arus. Pada teknik regulasi pada pembuatan catu daya, kita mengenal teknik regulasi daya linier dan teknik regulasi switching[5].
Dari uraian di atas, pada penelitian ini penulis akan merancang Konverter AC - DC 1 phasa dengan meregulasi keluaran tegangan, agar dapat digunakan sebagai catu daya listrik DC di labor listrik universitas batanghari.

\section{TINJAUAN PUSTAKA}

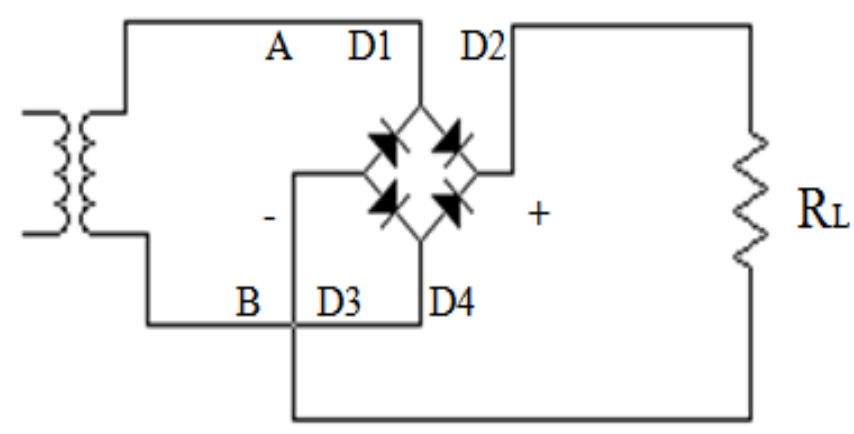

Gambar 1. Rangkaian Penyearah Sistem Jembatan [2]

Pada saat terminal A positif dan terminal B negatif, dioda-dioda $\mathrm{D}_{2}$ dan $\mathrm{D}_{3}$ berada dalam kondisi menghantar seadangkan $D_{4}$ dan $D_{1}$ tidak menghantar. Pada saat terminal A negatif dan B positip, dioda yang menghantar adalah $\mathrm{D}_{4}$ dan $\mathrm{D}_{1}$, sedang $\mathrm{D}_{2}$ dan $\mathrm{D}_{3}$ tidak menghantar.

Dengan demikian setiap setengah perioda tegangan bolak balik ada dua dioda yang menghantar 
(conduct) secara bersamaan dan dua buah dioda lainnya tidak menghantar sehingga menghasilkan bentuk gelombang penuh. Tegangan rata-rata $\left(\mathrm{U}_{\mathrm{dc}}\right)$ sama dengan sistem penyearah dengan menggunakan trafo CT Bentuk gelombang keluaran (output) terlihat seperti gambar 2 dibawah.

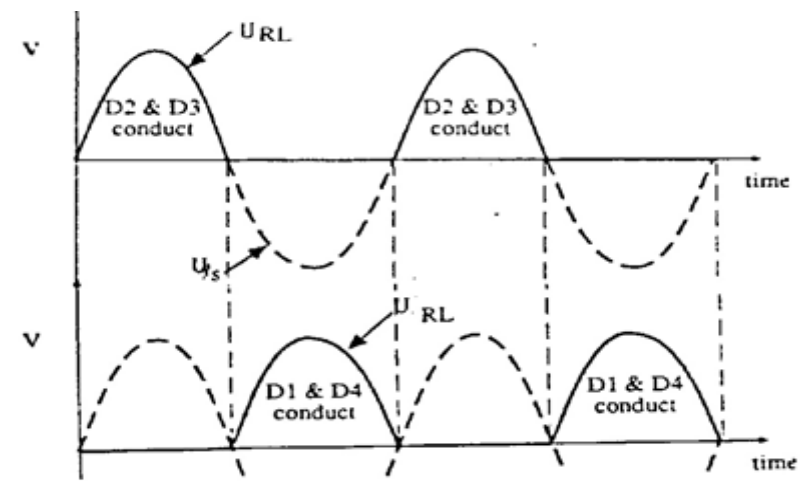

Gambar 2. Bentuk Gelombang Tegangan Keluaran [2]

\subsection{Filter}

Setiap gelombang keluaran hasil penyearahan baik yang tanpa filter maupun yang dengan filter terdiri atas komponen DC dan komponen AC (ripel). Akan tetapi sumber tegangan baterai/accu tidak mempunyai komponen AC[3]. Semakin baik kualitas suatu catu daya berarti semakin kecil perbandingan antara nilai komponen AC (ripel) terhadap komponen DC

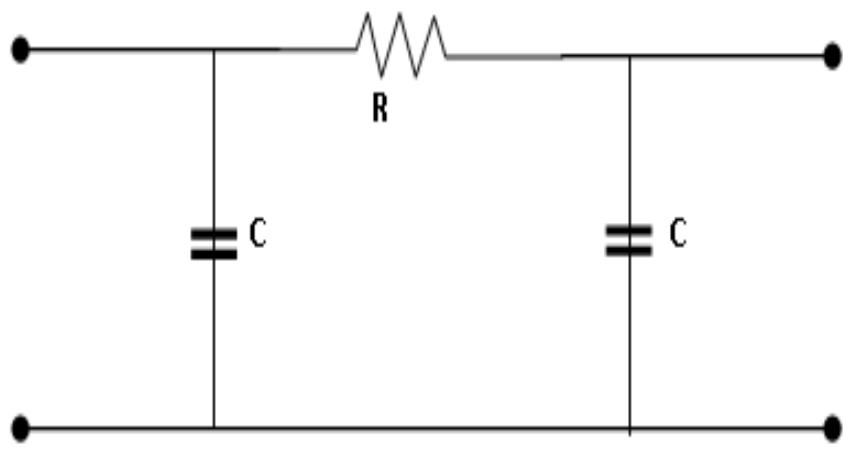

Gambar 3. Rangkaian Filter Pasif [6]

Untuk memperoleh keluaran catu daya yang lebih halus dapat digunakan filter RC, yakni gabungan antara komponen $\mathrm{C}$ dan $\mathrm{R}$.

$$
r=\frac{1}{4 \sqrt{3} f R C}
$$

\section{METODOLOGI}

Pada perencanaan Regulasi tegangan DC hasil penelitian menitik beratkan pada bentuk keluaran tegangan DC dengan filter pasif guna mengurangi riak gelombang pada keluaran DC dari dioda.

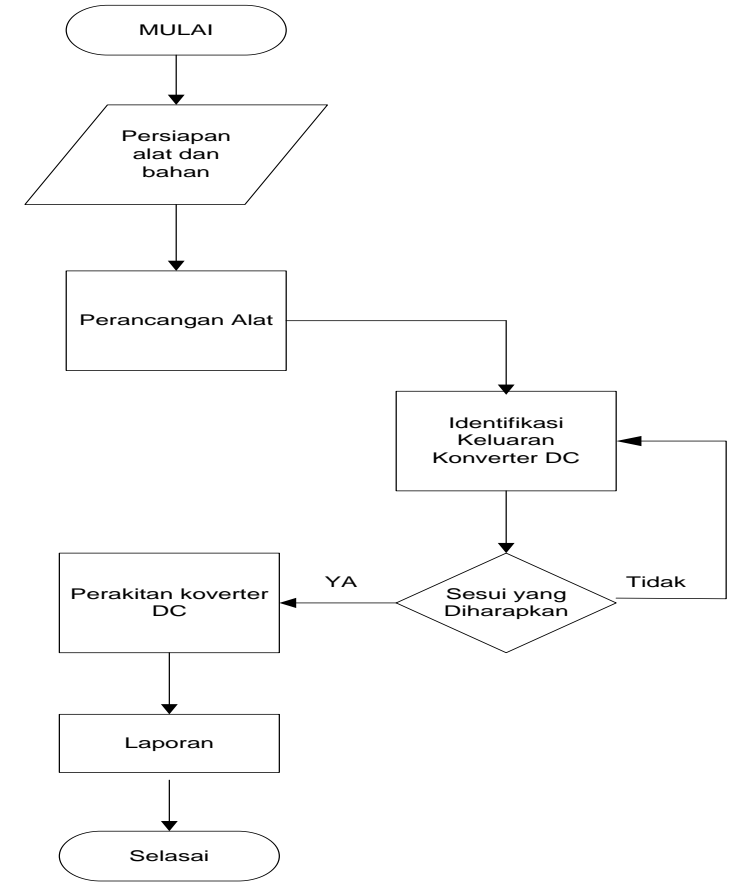

Gambar 4. Flowchart Penelitian

Pada penelitian ini, tegangan input AC PLN diregulasi tegangannya menggunakan regulator Transformator, dimana setiap tegangan keluaran AC dari transformator akan di identifikasi menjadi keluaran DC menggunakan Dioda sebagai penyearah yang kemudian akan diberikan filter pasif untuk mengurangi ripple tegangan.

\subsection{Line Diagram Penelitian}

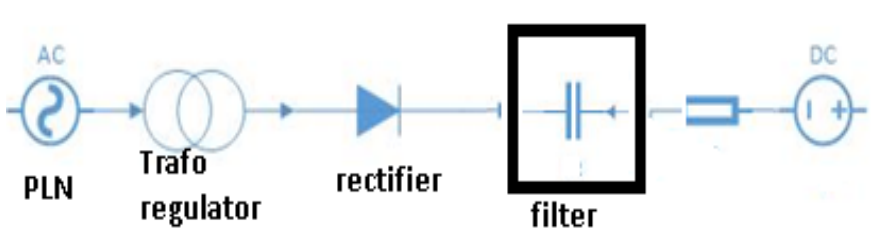

Gambar 5. Single Line Diagram Konverter AC ke DC

Dari gambar 5 diatas, terdapat beberapa komponen yang terhubung dari satu rangkaian ke rangkaian lain, dimana masing-masing kompenen mempunyai fungsi berdasarkan prinsip kerjanya.

\section{HASIL DAN PEMBAHASAN}

Pengujian ini dilakukan untuk memperlihatkan bentuk gelombang input dari konverter AC - DC, dimana transformator digunakan sebagai catu daya Arus bolak-balik (AC) yang akan dikonversikan menjadi arus searah (DC). Masing - masing dari pengujian ini variasi dari tegangannya adalah $25 \mathrm{VAC}, 50$, VAC, $75 \mathrm{VAC}$, $100 \mathrm{VAC}, 125 \mathrm{VAC}, 150 \mathrm{VAC}, 175$, 200VAC dan 220VAC. Untuk melakukan pengujian transformator ini dilakukan pengukuran menggunakan osciloscop (GOS$622 \mathrm{G}$ ), hasil pengukuran berturut-turut diperlihatkan pada gambar 6 dibawah. 


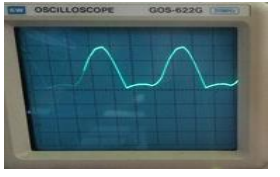

(a)

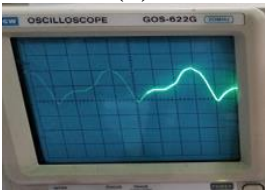

(c)

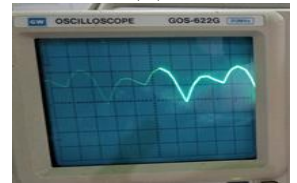

(e)

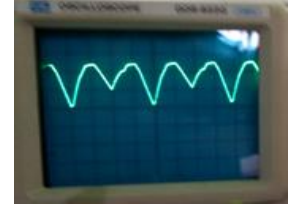

(g)

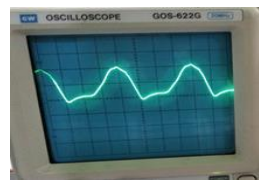

(b)

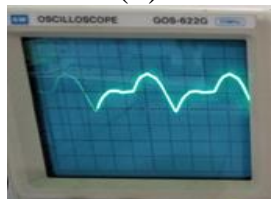

(d)

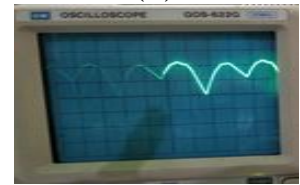

(f)

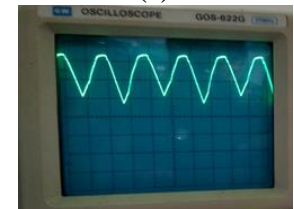

(h)
Gambar 6. Keluaran transformator (a) 25 Volt, (b) 50 Volt, (c) 75 Volt, (d) 100 Volt, (e) 125 Volt, (f) 150 Volt, (g) 175 Volt, (h) 200 Volt

Hasil pengukuran tegangan AC - DC diperlihatkan pada tabel 1 dibawah.

Tabel 1. Parameter Tegangan AC-DC

\begin{tabular}{cc} 
Tegangan AC (Volt) & Tegangan DC (Volt) \\
\hline 25 & 16 \\
50 & 31 \\
75 & 46 \\
100 & 62 \\
125 & 79 \\
150 & 94 \\
175 & 110 \\
200 & 126
\end{tabular}

Grafik hasil pengukuran tegangan DC teregulasi diperlihatkan pada gambar 7 dibawah.

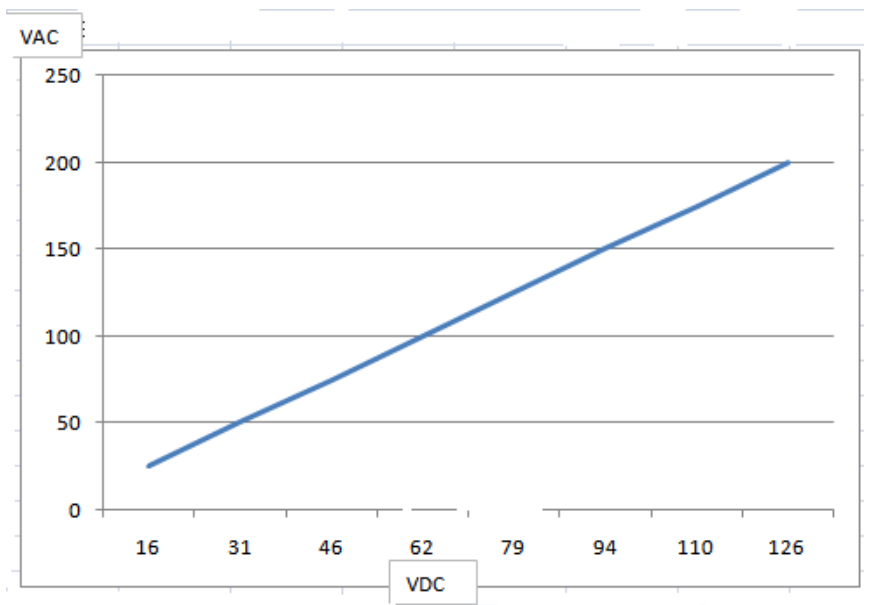

Gambar 7. Grafik keluaran Tegangan AC -DC
Bentuk keluaran DC diberi filter pada sumber AC tegangan 25 Volt diperlihatkan pada gambar 8 dibawah.

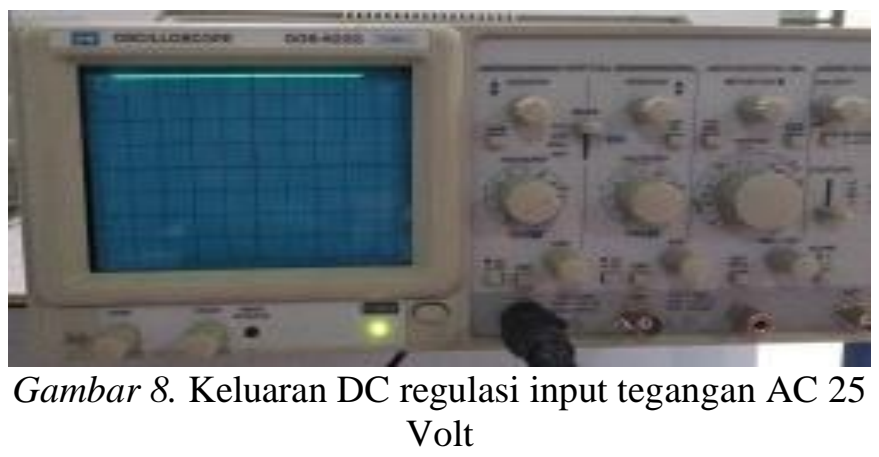

\section{KESIMPULAN}

Dari Penelitian yang telah dilakukan penghalusan tegangan kerut (Ripple Voltage Filter) dilakukan dengan menggunakan filter pasif dan didapat drop tegangan dari filter rata-rata sebesar 64\%, pengaturan (regulasi) oleh rangkaian regulator, penyediaan sumber energi listrik DC ini adalah untuk penyediaan tegangan variabel searah (DC) yang bertujuan untuk Penyediaan alat praktek pada labor listrik universitas batanghari

\section{DAFTAR PUSTAKA}

[1] Ambran.H, dkk ,"Perancangan dan Pembuatan Rectifier Penguant DC $30 \mathrm{KV}$ untuk Optimasi Polling pada Film Tipis PVDF," Jurnal ILMU DASAR, Vol.15, No.1, Januari 2014.

[2] Ahmad.A.A,"Rangkaian Penyearah Setengah Terkendali Tiga Fasa Untuk Pengendalian Karakteristik Motor Arus Searah Shunt,"Juranl Ilmiah Foristek, Vol.1, No.1, September 2011.

[3] Atmam,"Penggunaan Filter Kapasitif Pada Rectifier Satu Phasa dan Tiga Phasa Menggunakan Power Siulator (PSIM)," Jurnal Sain, Energi, Teknologi \& Industri, Vol.2, No.1, Desember 2017.

[4] Atmam, dkk,"Analisis Pengaruh Perubahan Tegangan dan Frekuensi Sumber Terhadap Tegangan Keluaran Rectifier," Prosiding Seminar Nasional Pakar ke 3 Tahun 2020.

[5] N.MOHAN, book, 1st ed., vol.1. USA:Don Fowley, 2012.

[6] Muhammad Ridwan.A.S,"Analisa Pemanfaatan Harmonisa Sebagai Sumber Energi Alternatif dengan Filter Pasif," Jurnal Nasional Teknik Elektro, Vol.7, No.3, November 2018.

\section{Biodata Penulis}

Agus Praosetyo, Lahir di jambi, 10 Agustus 1994, Menyelesaikan Pendidikan Diploma III di Universitas Batanghari Jambi jurusan Teknik Listrik.

Fajar Bima, Lahir di Solok, 08 Juli 1996, Menyelesaikan Pendidikan Diploma III di Universitas Batanghari Jambi jurusan Teknik Listrik.

Hendi Matalata, Menyelesaikan pendidikan sarjana di Institut Teknologi Padang jurusan teknik elektro pada tahun 2005. Pada tahun 2016 menyelesaikan pendidikan 
magister di Universitas Andalas jurusan teknik elektro.

Saat ini mengajar di Universitas Batanghari pada jurusan

teknik listrik dengan bidang riset semikonduktor,

konverter daya listrik dan kendali. 